\title{
Dos caras de la carrera docente: satisfacción y desmotivación
}

\author{
Encarnación Sánchez Lissen \\ UNIVERSIDAd de SEVILLA
}

\section{Resumen}

La enseñanza es una profesión que suscita posiciones controvertidas entre sus profesionales, entre los que la ejercen y en el conjunto de la sociedad. Esta pluralidad nos ha llevado a analizar en este artículo algunos factores que sobresalen e identifican a los aspirantes en su acceso a la carrera docente y posteriormente, en el ejercicio de la misma. En ambos confluyen momentos de satisfacción y de desmotivación. Pensando en esta dualidad, analizamos factores como la vocación, la motivación, el salario o las vacaciones del profesorado, entre otras, que provocan una consideración antinómica sobre la enseñanza.

Palabras clave: enseñanza, carrera docente, motivación, satisfacción, vocación, salario.

\section{Summary}

The teaching profession is regarded from different perspectives, even sometimes controversial, among those who belong to its own professional body, as well as in the whole society. This rich variety brings us to analyse in our paper some outstanding factors that identify the candidates in their access to the teaching career, and after that in their teaching practice. Both moments can show examples of satisfaction and non-motivation. Thinking of such duality, we analyse factors such as vocation, motivation, salary or even the teachers' holidays, which can provoke an antinomic consideration around the education.

KEYWORDS: teaching, educational career, motivation, satisfaction, vocation, salary.

\section{A modo de introducción}

Hemos titulado este artículo pensando que la enseñanza es una profesión con dos caras, una de satisfacción, que encarna la cara más amable y que hace grande a esta carrera y otra, la desmotivación, que es la más amarga y que suele estar representada por los problemas y los aspectos negativos que la envuelven. Si afortunadamente prevalece la pasión en el día a día de los enseñantes, también es preciso reconocer que las circunstancias de violencia, de crispación y de injusticia que existen actualmente en este entorno, están intimidando sobremanera la tarea apasionante de la función docente; con todo ello, desgraciadamente también se hace hueco la desmotivación. Es- 
tos incidentes no sólo afectan a los que afrontan día a día su profesión, también desconcierta a los estudiantes que aspiran a la enseñanza, a los que están por llegar a la carrera docente.

Compartirán con nosotros que no es el propio trabajo lo que hace desvanecer a los profesionales de la enseñanza y ni siquiera, la diversidad y amplitud de aspectos que deben atender o la multiplicación de deberes; realmente, las dificultades externas que le envuelven son, desde nuestro punto de vista, lo que más desgasta al profesional y también lo que más entorpece su desarrollo y disponibilidad, provocando buena parte de esa desmotivación. En general, todos los conflictos inherentes al trabajo pero externos al ejercicio del mismo, interfieren el interés y la vocación por el mismo; de manera particular, también sucede esto en la enseñanza. Con tristeza diría que estamos llegando a un cierto límite, porque es tanta la violencia que vemos día a día en los medios de comunicación y en la calle, y tanta la que se refleja en el entorno escolar, que nos hemos inmunizado. Muy a nuestro pesar, ese panorama está enturbiando incluso las expectativas de los nuevos y futuros estudiantes. En todo ello, la motivación ocupa un lugar muy destacado; no será en ningún caso la panacea, pero sí puede mejorar la eficacia del trabajo que se desempeña.

Ante la desmotivación se genera desaliento, además de confusión, negatividad, incertidumbre o estrés, provocando entre otras cosas el ya conocido "malestar docente" (Esteve, 1987, 2003). Aunque se trata de una de las reacciones más notoria entre los profesionales de la enseñanza, la desmotivación también convive en los momentos iniciales de la misma como es el acceso a la carrera docente, a la que llegan muchos estudiantes "de rebote" y en algunos casos, por no contar con la nota de corte necesaria para acceder y cursar otros estudios. Pero aun más, la desmotivación también está en el "ambiente social", una circunstancia que presiona directamente sobre el ejercicio profesional de este colectivo a los que embauca y contagia su labor.

Sarramona (2000) al referirse al malestar docente especifica como una de sus causas la "baja consideración social de esta profesión", una circunstancia que genera en algunos casos una cierta insatisfacción personal hacia la profesión. Con este indicador el autor explica que, un amplio número de docentes, acceden a esta profesión por la falta de posibilidades para hacerlo en otras carreras y profesiones de mayor prestigio social, un elemento que llega a ser el detonante de "un permanente estado de frustración personal" (Sarramona: 2000, 103).

Está claro que la pasión y la desmotivación colman esta profesión. Pues bien, para argumentar lo primero bastará con sentirla y con vivir la enseñanza desde el interior, desde la motivación interna. Desde ella se obtiene una recompensa personal y profesional, que será a la vez, un logro para la propia profesión. Para reconocer lo segundo sólo hace falta echar un vistazo a todos esos factores que interfieren negativamente en el desarrollo de la actividad docente. Entre ellos sobresalen factores relacionados con aspectos externos e internos de la profesión, con los procesos educativos y con los agentes implicados en la acción.

Entre lo que apasiona al profesor, Bazarra, Casanova y García Ugarte $(2004,58)$ señalan entre otros, el emprender nuevos caminos, los obstáculos como retos, el percibir y sentir que aprenden, las respuestas de los niños o sus miradas y sus sonrisas; y entre lo que les desmotiva, Torres (2006, 32-118) ${ }^{1}$ expone un extenso balance de los principales factores que inciden en dicha desmotivación.

Inquietos por esta dualidad, advertimos que existen dos momentos trascendentales en la vida del docente en los que se entremezcla la satisfacción y la desmotivación; éstos son por un lado, la etapa previa a la elección de los estudios de Magisterio en la que sobresale el factor más pasional y por otro, la etapa de desarrollo profesional propiamente dicha en la 
que prevalecen factores negativos y decadentes. Ambas etapas van a determinar en buena medida una dimensión holística del sentir y del logro de satisfacción que lleguen a disfrutar estos profesionales.

Siguiendo esta máxima, exponemos a continuación algunos factores que sobresalen en cada una de esas dos etapas mencionadas y gracias a los cuales, se logra inclinar la balanza bien hacia la satisfacción o bien hacia la desmotivación. Desde nuestra experiencia personal y desde el tratamiento científico de este tópico, nos ocupamos del carácter dispar pero paralelo que caracteriza a la vida académica y profesional del docente.

\section{Primera etapa. El acceso a los estudios de maestro: un desencuentro de intereses}

Es bastante desigual el entusiasmo que manifiestan los estudiantes al acceder a la universidad. Para unos, seguir estudiando es una simple rutina y pasan del bachillerato a la enseñanza superior sin reparar en ningún tipo de interés ya personal o profesional; para otros, es una cuestión de prestigio social y el acceso a la universidad marca su propio futuro. También en otros casos la universidad es un referente, a ella llegan eufóricos y especialmente motivados para estudiar determinadas carreras; se lo plantean como un objetivo a medio plazo. Es una suma de decisiones. En cada momento, la motivación tiene un papel muy distinto. Si para algunos la elección de una carrera es una etapa más o menos larga de toma de decisiones, para otros, es producto del azar; lo que Rivas (1990) denomina: "fortuismo situacional".

Aunque parezca algo frívolo, no pocos estudiantes eligen su carrera casi "a pie de ventanilla", es decir, tan sólo unos segundos antes de entregar la prescripción en una facultad, en una universidad determinada. En estos casos podemos pensar que los aspirantes muestran inseguridad en la elección de la carrera y que el azar ocupa un lugar destacado. En cualquier caso, es justo reconocer que la mayoría de estudiantes han elegido la carrera plenamente decididos y con un deseo claro por su elección, tras una maduración de la misma. En relación a estos datos, la Consejería de Educación y Ciencia de la Junta de Andalucía analizó en el curso 1998-1999 la opcionalidad de los estudiantes universitarios y comprobó que más del $75 \%$ accedían en primera opción a la carrera deseada. Asimismo, una investigación sobre los factores que inciden en los estudiantes de Magisterio para elegir su carrera señala que algo más del 60\% han elegido el Magisterio en primera opción; porcentajes que nos hacen valorar la sintonía entre la aspiración y la acción, así como el interés que demuestran los jóvenes por esta profesión (Sánchez Lissen: 2002, 98-99).

En esta misma línea, un estudio reciente elaborado por el Círculo Formación (2008) ${ }^{2}$, asegura que el $44 \%$ de los estudiantes de bachillerato eligen su carrera por vocación. Esta cifra se aleja un poco de las dos anteriores, aunque sigue ofreciendo ciertas expectativas de interés para casi la mitad de los aspirantes. En términos absolutos es bien significativo que algo más de la mitad de los jóvenes accede a unos estudios hacia los que, en principio, se sienten poco o nada motivados. Esta circunstancia es lo suficientemente de peso como para analizarla a fondo, reconocer en qué proporción se produce y finalmente, señalar algunas claves para su mejora.

La motivación se define como un factor mental que nos induce a la acción en todas y cada una de las situaciones y los ámbitos de la vida humana (García Sanchidrián: 2007, 19). Esto nos lleva a pensar, que llegar motivado a la carrera va a ser un factor de peso en el proceso de formación que desarrolla el estudiante. Sin duda, a lo largo de la misma se suscitarán otros elementos, también trascendentales, que influirán en la satisfacción y en el deseo por ejercer la profesión. Sin ser un valor absoluto, sin embargo, sí condiciona 
aunque sea relativamente los procesos ulteriores. Cabe preguntarse ante estos datos, ¿qué factores condicionan el acceso a la carrera de magisterio? En este sentido, diver- sos estudios realizados entre los años sesenta y noventa nos ofrecen resultados de enorme interés y que pasamos a interpretar. Algunos de ellos se exponen en la tabla 1.

\section{TABLA 1. MOTIVOS EN LA ELECCIÓN DE LA CARRERA DE MAGISTERIO}

\begin{tabular}{|c|c|c|c|}
\hline Autores & Objetivos & $\begin{array}{c}\text { Especialidades/ } \\
\text { Muestra }\end{array}$ & Motivos en la elección de la carrera de Magisterio \\
\hline $\begin{array}{l}\text { Bernardo de la } \\
\text { ROSA ACOSTA }^{3}\end{array}$ & $\begin{array}{l}\text { - Conocimiento de los } \\
\text { estratos sociales de } \\
\text { donde se reclutan los } \\
\text { candidatos al magiste- } \\
\text { rio, así como su medio } \\
\text { de origen. } \\
\text { - Conocer el peso de las } \\
\text { circunstancias socioeco- } \\
\text { nómicas en la elección } \\
\text { de estos estudios. }\end{array}$ & $\begin{array}{l}\text { En estos momentos, el } \\
\text { título de maestro no } \\
\text { contemplaba la forma- } \\
\text { ción por especialidades } \\
\text { Muestra: } 1.355 \text { alum- } \\
\text { nos de diversas } \\
\text { Escuelas de Formación } \\
\text { del Profesorado de } \\
\text { España. }\end{array}$ & 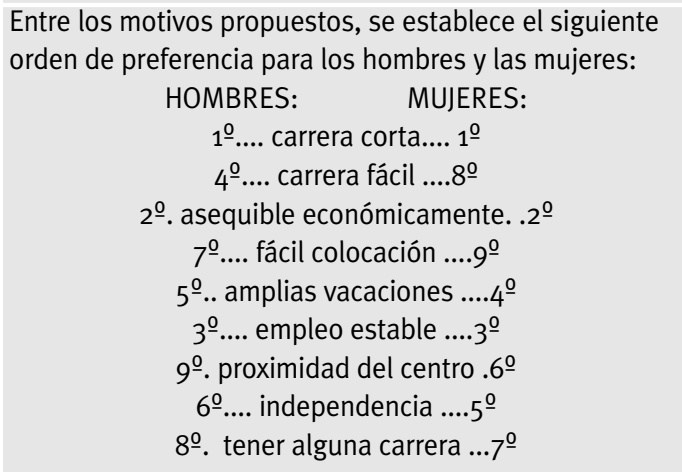 \\
\hline $\begin{array}{l}\text { Alfredo GÓMEZ } \\
\text { BARNUSELL }{ }^{4}\end{array}$ & $\begin{array}{l}\text { Conocer las principales } \\
\text { motivaciones que tuvie- } \\
\text { ron los maestros en la } \\
\text { elección de la carrera. }\end{array}$ & $\begin{array}{l}\text { Los cuestionarios fue- } \\
\text { ron realizados por } \\
\text { maestros en ejercicio. } \\
\text { Muestra: } 432 \text { maestros } \\
\text { nacionales. }\end{array}$ & $\begin{array}{l}\text { 1. Continuidad: } 39,9 \% \\
\text { 2. Origen social: } 38,7 \% \\
\text { 3. Influencia familiar: } 21,3 \%\end{array}$ \\
\hline $\begin{array}{l}\text { Félix ORTEGA } \\
\text { y Julia VARELA }\end{array}$ & $\begin{array}{l}\text { Analizar los procesos de } \\
\text { socialización, innova- } \\
\text { ción y adaptación de los } \\
\text { estudiantes de las EU. } \\
\text { de Profesorado de EGB. }\end{array}$ & $\begin{array}{l}\text { Especialidades de: } \\
\text { Ciencias, Filología y } \\
\text { Humanas. } \\
\text { Muestra: } 998 \text { sujetos; } \\
\text { 11,5\% del Universo. }\end{array}$ & $\begin{array}{l}\text { 1. Porque me gusta tratar con niños: } 37,9 \% \\
\text { 2. Porque tengo vocación: } 35,5 \% \\
\text { 3. Porque es una carrera corta (mayoritariamente hom- } \\
\text { bres) a través de la cual puede mejorarse la sociedad: } \\
15,5 \%\end{array}$ \\
\hline $\begin{array}{l}\text { Félix ORTEGA } \\
\text { y Agustín } \\
\text { VELASCO }\end{array}$ & $\begin{array}{l}\text { Analizar el profesorado } \\
\text { del entorno rural y el } \\
\text { perfil profesional de los } \\
\text { enseñantes. }\end{array}$ & $\begin{array}{l}\text { No se especifican las } \\
\text { especialidades. } \\
\text { Muestra: } 2.162 \text { maes- } \\
\text { tros rurales. }\end{array}$ & $\begin{array}{l}\text { A. Motivos circunstanciales: } \\
\text { 1. Falta de recursos económicos: } 46,4 \% \\
\text { 2. No había otros estudios en la provincia: } 32,8 \% \\
\text { 3. Mi familia quería que fuera maestro: } 22,7 \% \\
\text { B. Motivos más intrínsecos: } \\
\text { 1. Me gustaba tratar con niños: } 45,9 \% \\
\text { 2. Tenía vocación: } 42,5 \% \\
\text { 3. Profesión a través de la cual mejorar la sociedad: } 15,2 \% \\
\text { C. Motivos más extrínsecos: } \\
\text { 1. Era una carrera fácil: } 14,3 \% \\
\text { 2. Base segura para una promoción ulterior: } 7,3 \% \\
\text { 3. Profesión socialmente bien considerada: } 2,5 \%\end{array}$ \\
\hline $\begin{array}{l}\text { Rafael GARCÍA } \\
\text { ORTIZ }^{7}\end{array}$ & $\begin{array}{l}\text { - Conocer el origen } \\
\text { social de los estudian- } \\
\text { tes de magisterio; } \\
\text { - Indagar las causas y } \\
\text { factores que condicio- } \\
\text { nan su elección } \\
\text { - Conocer las circunstan- } \\
\text { cias económicas y la } \\
\text { tendencia vocacional de } \\
\text { los aspirantes. }\end{array}$ & $\begin{array}{l}\text { Participan alumnos de } \\
\text { tercer curso de magis- } \\
\text { terio (todas las espe- } \\
\text { cialidades). } \\
\text { Muestra: } 250 \text { alumnos. }\end{array}$ & $\begin{array}{l}\text { Con relación a los hombres, los factores que han influido } \\
\text { en la elección son: } \\
1^{0} \text { Es una carrera corta } \\
2^{0} \text { Asequible a su nivel económico } \\
3^{0} \text { La estima bastante independiente } \\
\text { Y en relación a las mujeres, los factores que han influido } \\
\text { en la elección son: } \\
1^{0} \text { La estima bastante independiente } \\
2^{0} \text { Es una carrera corta } \\
3^{0} \text { Asequible a su nivel económico }\end{array}$ \\
\hline
\end{tabular}




\section{TABLA 1. MOTIVOS EN LA ELECCIÓN DE LA CARRERA DE MAGISTERIO (CONTINUACIÓN)}

\begin{tabular}{|c|c|c|c|}
\hline $\begin{array}{l}\text { Mercedes } \\
\text { GONZÁLEZ } \\
\text { SANMAMED }\end{array}$ & $\begin{array}{l}\text { - Conocer y examinar las } \\
\text { razones que han llevado } \\
\text { a elegir la carrera de } \\
\text { Magisterio. } \\
\text { - Valorar la función } \\
\text { docente y su considera- } \\
\text { ción social y profesio- } \\
\text { nal. }\end{array}$ & $\begin{array}{l}\text { Participan estudiantes } \\
\text { de tercer curso de } \\
\text { magisterio. } \\
\text { Especialidades de: } \\
\text { Filología, Experimental, } \\
\text { Humanas y Preescolar. } \\
\text { Muestra: } 650 \text { alumnos }\end{array}$ & $\begin{array}{l}\text { A. Motivos idealistas: } \\
\text { 1. Trabajo con niños y adolescentes: } 4,13 \% \\
\text { 2. Oportunidad de ayudar a otros: } 3,87 \% \\
\text { 3. La importancia de la actividad de la enseñanza para } \\
\text { la sociedad: } 3,58 \% \\
\text { B. Motivos extrínsecos: } \\
\text { 1. Duración de la carrera: } 2,38 \% \\
\text { 2. Proximidad al lugar de residencia: } 1,94 \% \\
\text { 3. Nivel de dificultad: } 1,94 \% \\
\text { C. Motivos socio-culturales: } \\
\text { 1. La oportunidad de incrementar el nivel cultural: } 3,69 \% \\
\text { 2. Servir de trampolín para otros estudios: } 2,57 \% \\
\text { 3. Posibilidad de ser funcionario: } 2,56 \% \\
\text { D. Motivos académicos: } \\
\text { 1. Diversidad de asignaturas que componen el } \\
\text { currículum de la carrera: } 1,93 \% \\
\text { 2. Número de asignaturas de la carrera: } 1,27 \%\end{array}$ \\
\hline $\begin{array}{l}\text { Antonio } \\
\text { GUERRERO } \\
\text { SERÓN }{ }^{9}\end{array}$ & $\begin{array}{l}\text { Conocer las motivacio- } \\
\text { nes personales y las } \\
\text { sentidas por los compa- } \\
\text { ñeros, en torno a la } \\
\text { elección de la carrera. }\end{array}$ & $\begin{array}{l}\text { No se especifican las } \\
\text { especialidades. } \\
\text { Muestra: } 562 \text { profeso- } \\
\text { res estatales de EGB. }\end{array}$ & $\begin{array}{l}\text { A. Motivaciones personales generales: } \\
\text { 1. Trato con niños: } 51,3 \% \\
\text { 2. Continuidad: } 41,4 \% \\
\text { 3. Fácil acceso: } 30,7 \% \\
\text { B. Motivaciones personales de las profesoras: } \\
\text { 1. Trato con niños: } 57,7 \% \\
\text { 2. Continuidad: } 43,1 \% \\
\text { 3. Recomendación familiar: } 30,7 \% \\
\text { C. Motivaciones personales de los profesores: } \\
\text { 1. Falta de recursos: } 39,6 \% \\
\text { 2. Trato con niños: } 37,9 \% \\
\text { 3. Continuidad: } 37,9 \%\end{array}$ \\
\hline $\begin{array}{l}\text { Antonio } \\
\text { GUERRERO } \\
\text { SERÓN }^{10}\end{array}$ & $\begin{array}{l}\text { Analizar los procesos de } \\
\text { socialización anticipato- } \\
\text { ria y su influencia en } \\
\text { posteriores comporta- } \\
\text { mientos. }\end{array}$ & $\begin{array}{l}\text { Accedieron diversas } \\
\text { especialidades (sin } \\
\text { determinar). } \\
\text { Muestra: } 430 \text { diploma- } \\
\text { dos en Magisterio. }\end{array}$ & $\begin{array}{l}\text { 1. Motivos vocacionales e intrínsecos: } 2 / 3 \text { de la muestra. } \\
\text { - Trato con niños; } 46,2 \% \\
\text { - Vocación: } 19,9 \% \\
\text { - Deseo familiar: } 0,3 \% \\
\text { 2. Motivos sociales o extrínsecos: } 1 / 3 \text { de la muestra. } \\
\text { - Carencia de recursos: } 11,2 \% \\
\text { - Carrera fácil: } 6,2 \% \\
\text { - Buena remuneración: } 3,1 \%\end{array}$ \\
\hline
\end{tabular}

En estas tablas se exponen algunas de las investigaciones más destacadas sobre el reclutamiento y el acceso de los estudiantes al magisterio, que se han realizado en nuestro país en las cuatro últimas décadas del siglo Xx. A la vista de estos datos, advertimos que el acceso a una carrera no está vinculado a un único factor, sino que son varios los motivos que rodean en cada caso la elección. En ello ha influido también el momento histórico, ya que algunos de los indicadores que fueron relevantes en los años setenta, no tienen en la actualidad la misma trascendencia e incluso, se han ido desvaneciendo de una investigación a otra. Concretamente, uno de ellos es el factor económico, un indicador categórico y motivador en aquel momento pero que en la actualidad ocupa un lugar secundario. De igual forma, hoy existen otros elementos que inciden con fuerza en la elección, mientras que hace algunos años pasaban desapercibidos. Por ejemplo, en estos momentos, el acceso de estos profesionales al mundo laboral se encuentra bastante más restringido que hace algunos años; circunstancia que no pasa desapercibida para los as- 
pirantes, y por lo demás, las actuales notas de corte condicionan buena parte de los deseos más personales o profesionales de cualquier candidato. Ciertamente, las diferencias sin ser excesivas, se agudizan en las distintas especialidades.

Revisando las consideraciones expuestas en cada investigación, advertimos una serie de factores internos y otros externos al propio individuo que contribuyen básicamente en la elección de la carrera de magisterio y que provocan en los candidatos aspectos positivos y negativos; son factores que les desmotivan y factores que logran apasionar a los profesionales que forman. Entre los principales valores externos se encuentran, por una parte, las cualidades de la propia carrera, es decir: por ser "una carrera corta", o por tener acceso a "una promoción ulterior"; y por otra, se señalan cualidades que están relacionadas con el propio sujeto como son: los recursos económicos y también los académicos (tener la nota necesaria). Entre los valores internos prevalecen aquellos que están relacionados con las actitudes humanas y muy especialmente con las actitudes afines a la carrera. Es decir, está en relación con la inclinación o el "gusto" por la tarea docente, el trato con los niños y también, con el deseo de colaborar desde este trabajo en la sociedad. Con esta suma de fuerzas podemos reconocer que, hasta este momento, la balanza se inclina más hacia la satisfacción.

Álvaro Marchesi $(2008,47)$ considera que "tradicionalmente el acceso a los estudios de Magisterio atrae a alumnos con menor preparación o con más dificultades para dedicarse a carreras de mayor duración". Pues bien, en el proceso de elección se entremezclan dos sensaciones distintas y contrapuestas: las ilusiones con las incertidumbres. En torno a cada una de ellas les puede llegar a "dominar" un deseo, también los sueños personales, e incluso las ambiciones más íntimas; todos ellos son factores que inter- ceden en sus decisiones. Frecuentemente, en el ámbito de la enseñanza superior, encontramos estudiantes que no acceden a la carrera por propio convencimiento sino por influencia generacional; en otros, sin embargo, esta misma realidad ha desplegado sobre el sujeto el efecto contrario, desencadenando un rechazo hacia la profesión ejercida por padres y/o abuelos. Pero, y la vocación, ¿qué valor tiene en este proceso?

\subsection{La vocación: un valor intermedio.}

Es de sobra conocido el lugar que ocupa la vocación en el ámbito de la enseñanza y la importancia que tiene la elección vocacional (Gervilla: 1998). Tradicionalmente, la vocación ha estado vinculada con un sentimiento religioso o con la inspiración a algún estado concreto; si bien, al margen de este contenido, el término vocación también hace referencia a la inclinación que el individuo manifiesta hacia una profesión o por una carrera concreta. Realmente, no consideramos que los términos vocación y profesión sean excluyentes, sino más bien complementarios y de hecho, la práctica docente gozará de mayores éxitos si se combinan ambos de una manera equilibrada.

Ciertamente, no parece fácil medir cuantitativamente la vocación de cada uno, ya que se trata de un término ante el que no cabe tan sólo la posibilidad de responder sí o no; la vocación es un concepto que necesita analizarse a través de distintos indicadores, de valorar su intensidad desde su proximidad con otros elementos o desde la racionalidad versus idealización del mismo.

Desde el ámbito de la psicología, lo vocacional es para el profesor Rivas (1990, 26): "Un proceso psicológico cognitivo-comportamental gradual que lleva al individuo a la socialización de la vida adulta plena, realizable a través del empleo del tiempo útil o productivo, y desarrollado a lo largo de la vida en el mundo laboral u ocupacional". 
Desde otra perspectiva, los profesores González Blasco y González Anleo (1993, 75) han verificado el valor que tiene la vocación en las tareas docentes y el lugar que ocupa, al considerarla: "el motivo más importante para dedicarse a la enseñanza, junto a otras razones como el humanismo de la profesión o la facilidad y conveniencia de la carrera de profesor".

Asimismo, la elección vocacional es una dimensión íntimamente vinculada a la elección profesional. Esta tarea está asociada a distintos momentos de nuestra vida, así como a distintas edades. En cada caso, las razones que la determinan son muy diversas y están supeditadas a circunstancias sociales, personales, culturales y económicas, entre otras, que influyen en dicha decisión. Ante ello, el "concepto" que tiene cada uno de sí mismo es un factor significativo en el proceso de elección y realmente, muchas de las "indecisiones vocacionales" que se originan se han suscitado por la falta de confianza en uno mismo, o bien, por mostrarse incompetente para asumir una serie de roles de cara a su familia o a la sociedad.

En cualquier caso, entendemos que la orientación vocacional es prioritaria en ésta y en otras carreras y de hecho, será fundamental que dicha orientación pueda estar coordinada con cada sujeto, adecuándose a ellos, a sus condiciones y también a su propio sistema de valores que ayude a optimizar sus propias señas de identidad.

Durante la juventud, la toma de decisiones va a reorientar buena parte de su futura actividad profesional y precisamente, la elección de la carrera, es uno de esos momentos. En principio, aunque sin hacer de ello una estrategia absoluta, el formar parte de una determinada clase social ha marcado las pautas de participación de los individuos en un entorno determinado. Pues bien, esta "herencia", como la califican Varela y Ortega (1984), tiene su influencia en ámbitos del ser humano como puede ser el éxito escolar o, en la proyección de su futura práctica profesional docente, entre otros.

De hecho, para Carlos Alonso (1986), las situaciones que influyen en la elección de la carrera son principalmente dos: la clase social y lo que él llama la "cultura de poderes", en torno a la cual se han creado una serie de necesidades, de ilusiones e incluso de frustraciones, que han originado entre otros, una escala de prestigio en las carreras y profesiones.

En otro orden de cosas, la elección de una carrera ha sido catalogada por determinados autores en función de las tareas previas que la determinan. Así, Adams y Garrett (1974) especifican que dicha actividad comprende fundamentalmente tres etapas: la primera consiste en reunir información acerca de las posibilidades ocupacionales que son de especial interés para el joven; la segunda, llegar a una apreciación realista de las propias aptitudes, intereses y habilidades; y la tercera, elegir una carrera cuyas exigencias sean razonablemente compatibles con sus propias capacidades e intereses.

Actualmente no descartamos su influencia y su valor en la toma de decisiones, aunque parece evidente que estos tres requisitos no tienen para los jóvenes de hoy la misma intensidad. En la mayoría de los casos otras circunstancias frenan e influyen en la propia elección.

Siguiendo en esta misma línea, para J. Carlos Tedesco (1997), la elección de la carrera (de Magisterio), es la primera etapa de una secuencia concreta a través de la cual se construye un docente. Los dos restantes que conforman este proceso de construcción son: la formación inicial y el desempeño profesional.

Si tenemos en cuenta todas estas circunstancias, podemos llegar a comprender que la trayectoria académica de un alumno junto a su expediente académico y a su clase social (Varela y Ortega: 1984), tienen un importante papel a la hora de elegir la carrera 
de Magisterio. Así, si para los de una clase social alta, esta circunstancia puede originar un descenso en cuanto a su satisfacción personal, por el contrario, aquellos que pertenecen a una clase inferior pueden obtener a cambio un sentimiento de promoción importante.

Motivos como éste nos hacen pensar en los aspectos limitadores con los que tienen que enfrentarse aquellas personas que desean acceder al Magisterio. Pero tampoco son triviales los indicadores sociales-culturales, políticos, económicos y educativos; todos ellos también condicionan la elección de esta carrera.

\subsection{La motivación: un camino hacia la vocación}

Todas estas causas han llevado a establecer, por parte de diversos autores, una clasificación concreta para diferenciar los tipos de factores que han influido en su elección y en qué medida lo han hecho. Tras repasar distintos estudios, nos permitimos agrupar en dos, los tipos de factores influyentes en la elección; por una parte, aquellos que se advierten como limitadores de este acceso y por otro, los motivacionales. Realmente, no siempre es fácil mantener un equilibrio entre ellos; con lo cual, si el peso de las limitaciones es alto, necesitamos contrarrestarla desde la dimensión motivacional. En un tipo de decisión como ésta, difícilmente vamos a encontrar un modelo de motivación puro, sino otro en el que converjan ambos.

Fácilmente podemos reconocer a la motivación como un factor inductor en cualquier inclinación vocacional; un concepto que define el propio Madariaga (1996) como un conjunto de procesos que están implicados en la activación, la dirección y el mantenimiento de la conducta.

De una manera genérica apuntamos hacia dos modelos de motivación: uno externo y otro interno. Ambos tienen en este campo un valor incontrovertible ya que están muy ligados a los procesos de toma de decisiones que prevalecen en un individuo, así como a las preferencias y las satisfacciones personales. En este proceso motivacional entendemos que es fundamental la confianza que demuestre el sujeto en sí mismo y también, si es un buen conocedor de sus posibilidades y de sus carencias, ya que de esta forma se adecuará mejor a sus propias necesidades.

Buena parte de todas esas motivaciones externas están vinculadas a los agentes externos y a los factores particulares de cada contexto sociocultural.

En estos casos, la decisión se puede encontrar amparada por motivos íntimamente ligados a un sistema de valores, en el que prevalece la ayuda y el interés por los demás. Precisamente, esta expresión nos puede ayudar a entender la cita del profesor Beltrán (1998), cuando indica que la motivación está en el estudiante y no está en la tarea. Sin embargo, ello no nos impide pensar que la tarea llega a ser, en muchos casos, un medio más o menos motivador para alcanzar el fin deseado. En esta misma línea podemos pensar que entre un buen número de estudiantes, lo vocacional es sencillamente, la causa principal de la elección.

En relación a muchos de estos indicios a los que nos hemos referido: motivaciones, intereses personales, actitudes hacia la carrera, etc., entendemos que sería realmente triste reducir, hoy por hoy, la elección de la carrera a dos criterios: la oferta de plazas que lanza cada universidad y la referencia numérica que se recoge en el expediente académico del alumno. Realmente, todos los requisitos mencionados son un cúmulo de factores con los que hay que contar para obtener en el ámbito académico la mayor satisfacción posible y posteriormente, también en el profesional. En cualquier caso, entendemos que el acceso a una carrera va a estar condicionado por una parte, por la elección individual, y por otra, por la selección institucional. Aun con todo ello, la mayoría 
de las investigaciones consultadas nos demuestran que han primado los gustos personales para la elección. Verdaderamente, la etapa de acceso a la carrera docente vive envuelta en grandes momentos de satisfacción para sus aspirantes.

\section{Segunda etapa. El desarrollo de la profe- sión docente: pasión versus desmotivación}

Si durante los años de formación el estudiante de magisterio crece profesional y personalmente, cuando se acerca al ámbito laboral, comienza una nueva etapa de afianzamiento y de consolidación de lo aprendido y experimentado anteriormente. En algunos casos se clarifican los sentimientos y en otros se diversifican.

La profesión docente está cargada de matices, unos despiertan la pasión por la enseñanza pero otros desmotivan a sus actores. Algunos están relacionados con factores externos y otros con factores internos y más personales. En unos influyen los ideales y en otras la realidad.

Sin despreciar aquellos valores más intrínsecos como la vocación, en la enseñanza existen múltiples factores que motivan a este colectivo. Varios estudios han demostrado la importancia e influencia que han tenido y siguen teniendo muchos de ellos; entre otros: el salario, las vacaciones, el trato con los niños, los horarios laborales, etc. De estos factores nos centramos en los dos primeros para este artículo; y lo hacemos, no porque sean los más importantes pero sí porque son dos factores controvertibles tanto en cuanto, cuestiona a este colectivo y pone en entredicho su propia profesionalidad.

A pesar de ser factores que provocan satisfacción o desmotivación entre los docentes en activo, son también de los que turban al joven e indeciso estudiante; como decía antes, influyen no sólo sobre los que están, sino en los que están por llegar.

\section{3. $1 \mathrm{El} \mathrm{salario} \mathrm{del} \mathrm{profesorado}$}

¿Se ha preguntado alguna vez si la enseñanza es una profesión bien pagada? En principio nos surgen respuestas en ambas direcciones, así que intentaremos valorar cada una de ellas en su justa medida. Para comenzar, revelaremos el nivel salarial que disfrutan los docentes de otros países, haciendo buena la expresión utilizada por Goethe en la obra del Tasso: "si quieres conocerte a ti mismo, compárate con los demás". Sin ser una frase demasiado afortunada para algunos, sin embargo, podemos obtener desde un análisis particular, la manera de mejorar y arbitrar correctamente este indicador y asimismo, valorar los entresijos de este factor en los distintos países analizados.

Los datos de la OCDE confirman una parte de la respuesta a este argumento. En la siguiente tabla se ofrece el salario del profesorado según el informe de la OCDE del año $2004^{11}$. En ella se muestra el salario (en dólares) correspondiente a la media lograda una vez que el docente lleva como mínimo 15 años de experiencia, dado que se trata de un montante variable dependiendo del número de años que lleve ejerciendo la profesión. En algunos países como Grecia o Portugal, e incluso en el caso español, este dato varía considerablemente ya que durante el primer periodo laboral el sueldo no alcanza el nivel de los últimos años de vida profesional y sin embargo, se logra uno de los mayores salarios en sus últimos años de profesión (Campuzano: 2005, 2).

En cualquier caso, podemos observar que en España, el salario es superior a la media de los países de la OCDE y de la Unión Europea. Esto, sin embargo, no parece percibirse en la población, especialmente entre la población afectada que, por lo general, valora negativamente la dotación recibida. Quizá sea una percepción tomada desde dentro, desde el día a día de la actividad y del conjunto de tareas conexas que giran en 
torno a ella, lo que la convierte en una profesión que desarrolla una gran actividad fuera del horario meramente "formal" y que desborda a la propia realidad. Posiblemente son tareas que no se computan, que no están visibles, pero que afectan al conjunto de la actividad que desarrollan los docentes. Acaso haya que entender estas condiciones

\section{TABLA 2. EL SALARIO DEL PROFESORADO}

\begin{tabular}{|c|c|c|}
\hline País & ducación Primaria & Educación Secundaria \\
\hline Alemania & 46.935 & 48.167 \\
\hline Australia & 43.991 & 44.139 \\
\hline Austria & 33.644 & 36.000 \\
\hline Bélgica (Fl.) & 39.050 & 39.463 \\
\hline Bélgica (Fr.) & 33.643 & 37.471 \\
\hline Corea & 48.875 & 48.754 \\
\hline Dinamarca & 37.925 & 37.925 \\
\hline Escocia & 45.616 & 45.616 \\
\hline España & 36.342 & 40.663 \\
\hline Estados Unidos & 39.740 & 40.088 \\
\hline Finlandia & 32.541 & 38.318 \\
\hline Francia & 31.090 & 33.548 \\
\hline Grecia & 28.646 & 28.646 \\
\hline Países Bajos & 40.588 & 44.669 \\
\hline Hungría & 14.512 & 14.512 \\
\hline Irlanda & 44.185 & 44.185 \\
\hline Islandia & 22.396 & 22.396 \\
\hline Italia & 28.731 & 31.291 \\
\hline Japón & 45.753 & 45.753 \\
\hline Luxemburgo & 63.769 & 83.390 \\
\hline México & 16.669 & 21.192 \\
\hline Noruega & 35.420 & 35.420 \\
\hline Nueva Zelanda & 36.063 & 36.063 \\
\hline Polonia & 10.263 & 10.263 \\
\hline Portugal & 31.635 & 31.635 \\
\hline Reino Unido & 42.046 & 42.046 \\
\hline República Checa & 19.994 & 19.994 \\
\hline Suecia & 29.522 & 30.420 \\
\hline Suiza & 51.956 & 55.115 \\
\hline Turquía & 18.416 & -- \\
\hline OCDE & 35.099 & 37.488 \\
\hline UE-19 & 34.684 & 36.911 \\
\hline
\end{tabular}

para comprender los valores numéricos que le atañen. En cualquier caso, los datos en cifras se reflejan en la tabla 2.

Para los dos niveles educativos, el sueldo de los españoles se encuentra por encima de la media, por lo que podríamos confirmar que nuestros profesionales se encuentran bien pagados, aunque para ello nos limitemos a contemplar simplemente los datos numéricos y dejemos en un segundo plano las tareas vinculadas a la misma.

Si analizamos los datos de una manera comparativa, se observa que Luxemburgo destaca entre todos los países europeos y en todos los casos. Asimismo, despuntan los países de Alemania, Dinamarca, Finlandia, Países Bajos, e Irlanda, en los cuales, el salario del profesorado novato es superior a la media europea en un $20 \%$; España, como decíamos antes, también está en este grupo.

En general, un profesional bien pagado es un valor añadido para la calidad de su actividad y en este caso, tampoco es en balde, aunque esto no lo dice todo. En realidad, esta variable tomada en sentido estricto no es representativa por sí sola, más bien adquiere un verdadero significado si se analiza junto a otros indicadores; por ejemplo, el número de horas de clase que tienen asignado los docentes de los distintos niveles educativos de cada uno de los países. Adentrándonos en estos valores, aunque sin intención de sobrecargar excesivamente de cifras este artículo, cabe reconocer según el Informe de la OCDE (2004) que, excepto en la enseñanza primaria en el que los docentes cumplen un total de 880 horas de clase al año, cifra algo superior a la media de la OCDE que se sitúa en 805, el resto de etapas educativas queda por debajo de la media. En la ESO el número de horas es de 581 y en la secundaria postobligatoria la suma total es de 564 horas. En ambos casos la media de la OCDE es de 704 y 663, respectivamente. Pues bien, aunque la relación lógica sería que a mayor número de horas, mayor salario, sin embargo en este caso, no se trata de una correla- 


\begin{tabular}{|c|c|c|c|c|c|c|c|}
\hline & Verano & Otoño & Navidad & $\begin{array}{l}\text { Invierno/ } \\
\text { Carnaval }\end{array}$ & $\begin{array}{c}\text { Primavera/ } \\
\text { S. Santa }\end{array}$ & $3^{0}$ Trimestre & $\begin{array}{c}\text { Días } \\
\text { festivos }\end{array}$ \\
\hline ALEMANIA & 6 semanas & 4-12 días & 7-13 días & 0-12 días & 4-12 días & o-11 días & 10 días \\
\hline DINAMARCA & 7 semanas & 7 días & 12 días & 7 días & 7 días & - & 5 días \\
\hline ESPAÑA & 11-12 semanas & - & 14 días & 2-3 días & 7 días & - & 7 días \\
\hline FINLANDIA & 10-11 semanas & 2-7 días & 7-14 días & 7 días & 3-4 días & - & 4 días \\
\hline FRANCIA & 9 semanas & 10 días & 14 días & 14 días & 14 días & - & 4 días \\
\hline INGLATERRA Y GALES & 6 semanas & 7 días & 14 días & 7 días & 14 días & 7 días & 1 día \\
\hline IRLANDA & 9-13 semanas & 7 días & 14 días & 2-7 días & 7 días & - & 2 días \\
\hline ITALIA & 13-14 semanas & - & 14 días & 1-4 días & 4-7 días & - & 5 días \\
\hline PORTUGAL & 9 semanas & - & 14 días & 3 días & 10 días & - & 8 días \\
\hline
\end{tabular}

ción directa. En cualquier caso se trata de un motivo de peso a considerar.

La Fundación Bofill ha publicado en el año 2008, un estudio en torno al profesorado catalán y dirigido por Francesc Pedró. En él se extraen datos sobre la mayor o menor satisfacción que muestra este colectivo por su profesión y de manera especial por algunos de los indicadores que más le caracterizan. En general, la opinión que se extrae es positiva ya que algo más de la mitad de los maestros dice sentirse "satisfechos" o "muy satisfechos" con su salario. Sin embargo, se extrapola una visión negativa al referirse a la inexistencia de una carrera profesional que les impide aumentar gradualmente el sueldo.

No nos gustaría finalizar este apartado con la sensación de que lo económico es un valor de primer orden e incuestionable, tanto para los aspirantes a la enseñanza como para los que están en el ejercicio de la misma; es importante, qué duda cabe, pero no es absoluto. Más bien convendrán con nosotros que, afortunadamente, la pasión en la enseñanza la marcan otros grandes valores, el valor de educar.

\subsection{Las vacaciones de los profesores}

Menudo atractivo tiene para cualquier persona las vacaciones que tienen -o parecen tener- los docentes. Es un asunto espinoso e incluso algo equívoco, donde la realidad supera, también en esta ocasión, a la ficción. De entrada, el periodo de vacaciones que tienen los alumnos de cualquier país, no coinciden en tiempo ni espacio con la que disfrutan los profesores. En este capítulo muchos profesionales se justifican señalando la cantidad de trabajo que se realiza al margen del trabajo directo con los niños y el tiempo que todo ello requiere. No les falta razón.

En la tabla 3 se exponen numéricamente las cifras relacionadas con las vacaciones en algunos de los países más destacados de la Unión Europea, según el Informe de Organización del Tiempo Escolar elaborado por la Comisión Europea en el curso 2005/2006 (EURYDICE:2006).

Aunque a priori las cifras nos parezcan muy semejantes, sin embargo, hay que reconocer que la diferencia radica fundamentalmente en la distribución del tiempo por 
trimestres; es decir, las mayores diferencias inciden más en el reparto de las mismas que en el número total de días de los que disfrutan en cada caso.

Tal como se aprecia en la tabla anterior, se apuntan en diversos periodos intervalos abiertos que demuestran la diversidad que, a su vez, se puede hallar en cada país. No son cantidades fijas o inmóviles sino cambiantes según la etapa escolar, el curso académico o las regiones, comunidades autónomas, provincias o lánders en los que se divide el país.

Para España, las vacaciones disfrutadas oscilan aproximadamente entre 107-115 días distribuidos en cinco periodos. Alemania tiene un intervalo bastante amplio ya que, según demuestran las cifras, las vacaciones están repartidas en siete periodos concretos pero difieren notablemente de un Lánder a otro; concretamente pueden bascular entre 70 y 110 días.

Finlandia, país que se encuentra hoy a la vanguardia en materia de educación gracias a los resultados publicados en todos los Informes Pisa (2000, 2003, 2006) nos muestra las vacaciones algo más distribuidas en el tiempo que en España, aunque el número total sea bastante semejante; concretamente se computa un total de 93-113 días.

Pues bien, a la vista de los datos, el factor vacacional es un valor muy significativo de esta profesión, tanto, que se puede convertir en un atractivo especial para los aspirantes a maestro o ser un elemento motivador para la elección de esta carrera, primero y en el transcurso de su profesión, después.

En principio se revela como un factor irrefutable que incide más en la satisfacción que en la desmotivación, aunque se trate de un factor recurrente para muchos e insinuante para otros. En general, las vacaciones son un factor externo en el proceso de motivación y hay que entenderlo como tal.

Aunque no sería justo por lo que representa la tarea de enseñar, cabe reconocer la influencia que tienen el factor vacacional como un elemento motivador en el ejercicio de la misma, aunque las vacaciones, por sí solas, no tienen el mérito suficiente para identificarlas como tal.

\section{A modo de conclusión}

Buena parte de los factores mencionados a lo largo de este artículo como son los factores externos: el salario, las vacaciones, el horario, etc., tienen un valor inconmensurable, pero otros como son los relacionados con los aspectos más íntimos de estos profesionales: la vocación, ilusiones o satisfacción personal, tampoco son despreciables.

A modo de conclusión y volviendo al objeto de este artículo cabe reconocer en la enseñanza, tanto en su formación como en su práctica, momentos dulces pero también otros amargos que incomodan el día a día de la profesión. En cada caso, en cada una de las etapas por las que camina el docente se perciben factores de uno y otro calibre, unos muy próximos a la pasión y otros más cercanos a la desmotivación. Realmente, durante el periodo inicial y de acceso a la formación definidos en la primera etapa, los matices externos a la propia profesión pueden llegar a marcar el gusto e interés por la propia carrera; sin embargo, predominan finalmente los valores más intrínsecos a la misma, tal como hemos podido comprobar por las investigaciones consultadas. En la segunda etapa, durante el periodo profesional, se juzga al docente en función de los diversos factores endógenos y exógenos que alberga su propia práctica, lo cual desencadena para algunos un trabajo pasional, pero algo desmotivador para otros. Desde nuestra propia experiencia, en la mayoría de los casos, los valores intrínsecos son los verdaderamente influyentes en el grado de aceptación, de entusiasmo y satisfacción de la profesión, mientras que los extrínsecos suelen desencadenar en mayor medida situaciones de 
desmotivación entre los profesionales. Sin ser un valor absoluto, ciertamente ocurre que "un sentimiento de desánimo y de impotencia lleva a la rápida conclusión de que no hay nada que hacer" (Camps: 2008, 205), pero en la enseñanza además de creer en la educación, tal como argumenta con solidez la profesora Camps, se trata también de creer cada uno en sí mismo; desde esa perspectiva, se podrá lograr una mayor satisfacción en el conjunto del ejercicio docente.

\section{Referencias bibliográficas}

Adams, S. y Garrett, J. L. (1974): Cómo ser buen maestro. Buenos Aires: Kapelusz.

Alonso Monreal, C. (1986): Tipología de estudiantes universitarios. Murcia: Secretaría de Publicaciones de la Universidad de Murcia.

Bazarra, L.; Casanova, O. y García Ugarte, J. (2004): Ser profesor y dirigir profesores en tiempos de cambio. Madrid: Narcea.

Beltrán Llera, J. (1998): “Claves psicológicas para la motivación y el rendimiento académico”, en Acosta, M. (Coord.): Creatividad, motivación y rendimiento académico. Málaga: Ediciones Aljibe, pp. 39-54.

Camps, V. (2008): Creer en la educación. Barcelona: Península.

Campuzano, A. (2005): "Europa necesita profesores... pero faltan candidatos". Revista del Colegio Oficial de Doctores y Licenciados en Filosofía y Letras y en Ciencias, 167, 2-3.

Esteve Zarazaga, J. M. (1987): El malestar docente. Barcelona: Laia.

Esteve Zarazaga, J. M. (2003): La tercera revolución educativa. Barcelona: Paidós.

EURYDICE (2006): Orgnisation of school time in Europe. Bruselas: European Commission.

García Garrido, J.L. (2006): La máquina de la educación. Barcelona: Ariel.

García Sanchidrián, J. (2007): Motivación: haga que lo hagan. Madrid: Fundación Confemetal.

Gervilla Castillo, E. (1998): “Educar hoy: profesión contra vocación”. Bordón, 50 (1), 83-91.
González Blasco, P. y González-Anleo, J. (1993): El profesorado en la España actual. Informe sociológico sobre el profesorado no universitario. Madrid: S.M.

Madariaga Orbea, J. Maㅗ (1996): “La motivación”, en Goñi, A. (Ed.): Psicología de la educación sociopersonal. Madrid: Fundamentos, pp. 73-87.

Marchesi, A. (2008): Sobre el bienestar de los docentes: competencias, emociones y valores. Madrid: Alianza.

Pedró, F. (2006): “Un diagnóstico de la situación del profesorado en España desde una perspectiva comparativa". Revista de Educación, 340, 243-264

Rivas Martínez, F. (1990): La elección de estudios universitarios. Madrid: Consejo de Universidades, Secretaría General.

Sánchez Lissen, E. (2002): Elegir enseñar: entre la vocación y la osadía. Sevilla: Edición Digital Atres.

Sarramona, J. (2000): Teoría de la educación. Barcelona: Ariel.

Tedesco, J. C. (1997): “Fortalecimiento del rol de los docentes”, en VV.AA.: Atreverse a educar. Madrid: Narcea, pp. 36-55.

Torres Santomé, J. (2006): La desmotivación del profesorado. Madrid: Morata.

Varela, J. y Ortega, F. (1984): El aprendiz de maestro. Madrid: Servicio de Publicaciones del MEC.

\section{Notas}

${ }^{1}$ El profesor Jurjo Torres en su libro: La desmotivación del profesorado (2006) expone las razones de dicha desmotivación asociada a 18 factores; éstos son: incomprensión de las finalidades de los sistemas educativos, formación inicial muy deficitaria, pobreza de las políticas de actualización del profesorado, concepción tecnocrática del trabajo docentes, un currículo obligatorio sobrecargado de contenidos, una Administración del Sistema Educativo burocratizante, falta de servicios de apoyo y de una inspección escolar, ausencia de una cultura democrática en los centros escolares, problemas de comunicación con el alumnado, dificultades para relacionarse con las familias, el profesorado como único responsable de la calidad de la educación, ambiente social de escepticismo y banalización, políticas de mercantiliza- 
ción y privatización, falta de incentivos al profesorado más innovador, una continua ampliación de las funciones encomendadas a la educación y finalmente, mayor visibilidad de los efectos del trabajo del profesorado.

${ }^{2}$ Se trata de un estudio elaborado por la Consultora Círculo Formación a partir de los datos de una encuesta realizada a los asistentes a la Feria de Universidades UNITOUR, celebrada entre noviembre de 2007 y febrero de 2008 en diversas provincias españolas. Puede encontrar una información más detallada con los resultados de la encuesta en la siguiente dirección:

http://lavozdeasturias.mynewsonline.com/pdf/index.php?screen=preview\&ref=PAS20080401Goo8 \&idioma=PER [consultado 20 de abril de 2008]

${ }^{3}$ Puede consultar ampliamente los datos de esta investigación en: ROSA ACOSTA, Bernardo de la (1968): La influencia del factor socioeconómico en la elección de la carrera de magisterio. Valencia, Biblioteca de la Universidad de Valencia. Se trató de una investigación a escala nacional.

${ }^{4}$ Puede consultar esta investigación en: GÓMEZ BARNUSELL, Alfredo (1972): El magisterio como profesión. Estudio sociológico del magisterio nacional en las Islas Baleares. Barcelona, Ariel.

${ }^{5}$ Para una información más detallada puede consultar: ORTEGA, Félix y VARELA, Julia (1985): El aprendiz de maestro. Madrid, CIDE. Se trata de una investigación vinculada a las escuelas estatales dependientes de la Universidad Autónoma y Complutense de Madrid.

${ }^{6}$ Puede consultar ampliamente esta investigación en: ORTEGA Félix y VELASCO, Agustín (1991): La profesión de maestro. Madrid, CIDE. Es una investigación llevada a cabo en Madrid, Castilla-La Mancha.

${ }^{7}$ Puede ampliar estos datos consultando la tesis doctoral del profesor: GARCÍA ORTIZ, Rafael (1983): La elección de la carrera de profesor de EGB. Importancia del factor socioeconómico-familiar. Sevilla, Facultad de Ciencias de la Educación, Tesis inédita. Esta investigación se llevó a cabo en la Escuela Universitaria del Profesorado de EGB de Sevilla.

${ }^{8}$ Puede consultar en la siguiente revista, otros datos de esta investigación: GONZÁLEZ SANMAMED, Mercedes (1995): "Motivos para estudiar magisterio: entre el idealismo y la profesionalización". En Adaxe, 11; pp. 65-75. Esta investigación se llevó a cabo en las Escuelas de Magisterio de Galicia (Coruña, Lugo, Pontevedra, Santiago y Orense).

${ }^{9}$ El siguiente texto expone ampliamente los datos de esta investigación: GUERRERO SERÓN, Antonio (1993): Maestras y maestros. Autonomía, práctica docente y sindicación en una profesión subordinada. Un estudio sociológico. Madrid, Univ. Complutense de Madrid.

${ }^{10}$ En el siguiente artículo se recogen parcialmente los datos de la investigación: GUERRERO SERÓN, Antonio (1995): "La construcción social del magisterio: orígenes sociales, trayectoria educativa y motivaciones profesionales". En Revista de Educación. 306; pp. 127-151. Esta investigación se llevó a cabo en diferentes Escuelas de Magisterio de toda España.

${ }^{11}$ OCDE (2004): Education at a glance 2004. París: OCDE. Puede consultar un resumen en español de los indicadores educativos en la dirección: http://www.oecd.org/dataoecd/33/24/33713498.pdf [consultado 7 de junio de 2006].

DIRECCIÓN DE LA AUTORA: Encarnación Sánchez Lissen. Universidad de Sevilla. Facultad de Ciencias de la Educación. Departamento de Teoría e Historia de la Educación y Pedagogía Social. C/ Camilo José Cela s/n. 41018. Sevilla.

Correo electrónico: eslissen@us.es

Fecha de recepción del artículo: 29.IX.2008

Fecha de aceptación definitiva: 25.I.2009 